\title{
A reduced reaction mechanism for the combustion of n-butane
}

\author{
Juan C. Prince ${ }^{\mathrm{a},{ }^{*}}$, César Treviño ${ }^{\mathrm{b}}$, Forman A. Williams ${ }^{\mathrm{c}}$
}

\begin{abstract}
A $\mathrm{C}_{1}-\mathrm{C}_{3}$ short chemical-kinetic mechanism (the San Diego mechanism), which involves 235 elementary reactions among 40 such species, is extended to $\mathrm{C}_{4}$ by adding 22 chemical-kinetic steps, among 7 additional species, with their associated reaction-rate parameters, to include the ignition and combustion of n-butane over a range of conditions that encompasses both lowtemperature and high-temperature chemistry, as well as both high and low pressures. Tests of predictions against measured ignition delays and laminar burning velocities are reported, as are comparisons with recent measurements in jet-stirred reactors, supporting the predictions of the mechanism, which may be useful in combustion computations, especially when larger mechanisms would be too time-consuming to be accommodated.
\end{abstract}

Keywords: n-Butane; Chemical mechanism; Modeling; Low-temperature oxidation; Flames 


\section{INTRODUCTION}

The characteristics of n-butane oxidation are of high interest in the field of combustion. This alkane fuel exhibits behavior similar to that of more complex hydrocarbons. Several studies have been published to determine its performance in flames [1-5] and in high- and low-temperature ignition [6-17]. These include experimental investigations in rapid-compression machines, in shock tubes, and in static and jet-stirred reactors, as well as numerical work with detailed kinetic mechanisms. Like other normal alkanes, n-butane exhibits different chemical-kinetic mechanisms for high-temperature ignition ( $\mathrm{T}>900 \mathrm{~K}$ ), which has been studied extensively, and for low-temperature ignition $(\mathrm{T}<700 \mathrm{~K})$, which, along with the negative-temperature-coefficient (NTC) range separating them, remains a challenging topic of research that has not been so thoroughly investigated thus far. In addition, the mechanisms that have been proposed generally are very extensive, and as a result it is not yet clear precisely which reactions and kinetic constants are most important over the full range of temperatures, from well below $700 \mathrm{~K}$ to well above $900 \mathrm{~K}$. The present contribution is directed towards these questions, roughly for pressures between $0.5 \mathrm{~atm}$ and $50 \mathrm{~atm}$, at temperatures within the reacting ideal gases ranging between about $500 \mathrm{~K}$ and $2500 \mathrm{~K}$, for equivalence ratios less than 2 or 3, in systems involving n-butane in air or in other oxygen/inert mixtures.

The high-temperature chemistry that occurs as temperatures approach the adiabatic flame temperature is especially critical for chemical-kinetic mechanisms of laminar flames. Marinov et al. [1] demonstrated the importance of a reaction sequence leading to the formation of aromatic compounds in a fuel-rich n-butane/argon/oxygen premixed flame, and they developed a kinetic model consisting of 680 reactions among 156 chemical species for this system, but because of the associated complexities we do not include aromatics in the present mechanism, which is a limitation on the phenomena that can be addressed by the description. The experimental burning 
velocities measured in [2-4], among the most accurate at normal atmospheric pressure for mixtures initially at room temperature ( $295 \mathrm{~K}$ to $298 \mathrm{~K}$ ), have been modeled successfully by Ranzi et al. [5] through a hierarchical analysis for laminar flame speeds of both hydrocarbons and oxygenated fuels, including $\mathrm{C}_{0}-\mathrm{C}_{4}$ compounds, on the basis of detailed kinetic mechanisms for pyrolysis and combustion at high temperatures. This last study is among the most useful investigations for developing an understanding of the dominant chemistry affecting laminarflame structures and burning velocities.

The low-temperature chemistry, not important in flames, makes itself felt instead in auto-ignition experiments. Ignition-time experiments with n-butane, completed in the 1990's [8-10], for pressures between 1 and 36 atm, at equivalence rations of 0.5-2.0, exhibited NTC behavior at some point in the temperature range from $550 \mathrm{~K}$ to $1000 \mathrm{~K}$ and are described very well by a comprehensive chemical model developed in that decade [11]. More recent experimental work [12-13] of this kind produced results that, as well as the earlier results [8-10], compare very favorably with predictions of a detailed reaction mechanism of 1328 chemical reactions including 230 species [13], which was developed on the basis of earlier work of Curran et al. [18], ultimately advancing our understanding of the chemical kinetics of these combustion processes significantly.

Even more recently, Battin-Leclerc et al. [14-16] experimentally investigated hydroperoxide formation in kinetic models for the oxidation of alkanes, including n-butane, at low temperatures in jet-stirred reactors, identifying the species responsible for low-temperature ignition [16]. By providing data on species concentrations, beyond just the overall ignition-time results, this work affords the possibility of making more stringent tests of predictions of chemical mechanisms. Most recently, Eskola et al. [17] employed photolytic initiation with mass-spectrometric measurements to study ketohydroperoxide formation at pressures up to 2 atm, indicating that the 
4-hydroperoxy-2-butyl radical, derived from $n$-butyl, is the main reactive radical leading to ketohydroperoxide, with 3-hydroperoxybutanal being the dominant ketohydroperoxide constituent observed. Their experimental results were consistent with those of Battin-Leclerc et al. [15-16], and they found some deviations from predictions of the previously mentioned mechanism [13]. The present work also addresses the jet-stirred-reactor experiments [16] and makes use of the findings reported in [17] to motivate selections of revisions of values of rate parameters in developing a reduced mechanism that produces reasonable agreement with both reactor measurements [16] and results of combustion experiments that span the full range from low-temperature to high-temperature chemistry.

With the present extension based largely on the relatively recent work [13], in that context the contribution reported here effectively reduces the system from 1328 reactions among 230 species to one involving 257 reactions among 47 species, which, in addition to possibly contributing to improved understanding of dominant chemical mechanisms, might also facilitate some computations that otherwise would not be feasible.

\section{THE REACTION MECHANISM}

Taking into account the recent chemical-kinetic studies of n-butane combustion processes identified above, the approach to be adopted here makes use of sensitivity analysis and of applicable steady-state approximations for reducing the size of the mechanism. Only those reactions that affect the ignition delay time and laminar burning velocity over the range of conditions of interest were retained, subject to consistency with the aforementioned concentration measurements in jet-stirred reactors.

The base mechanism consists of $\mathrm{C}_{1}-\mathrm{C}_{3}$ chemistry [19], tested for a wide range of parameters. In developing a reduced n-butane sub-mechanism, different detailed mechanisms were consulted [1, $5,11,13,20-23]$, with specific choices stated below. For the sake of consistency, wherever 
possible the new reaction rates and thermodynamic data were taken from the mechanism developed in the recent detailed chemical model reported in [13], although slight modifications of some rate parameters were made (as identified below), within uncertainties and with negligible effects on other predictions, for improving agreements with experimental results on laminar flame speeds, subject to consistency with recent more detailed results [16, 17]. This model was then reduced by deleting steps of lesser importance and by imposing applicable steady-state approximations.

Table 1 shows the final selection of the n-butane reaction scheme and its rate parameters, which are then to be added to the $\mathrm{C}_{1}-\mathrm{C}_{3}$ portion of the San Diego mechanism. That mechanism has additional steps in other sections, such as in the n-heptane sub-mechanism, that contain some $\mathrm{C}_{4}$ species not present in the table, such as butadiene, but those species (which can be included if desired, bringing the total prior to the present additions to 243 steps among 42 species) are not needed in addressing the n-butane problems considered here. Without those species, the rest of the mechanism involved only 235 elementary steps among 40 species, and, basically, only 22 new reactions are added that involve just 7 new species $\left(n-\mathrm{C}_{4} \mathrm{H}_{10}, n-\mathrm{C}_{4} \mathrm{H}_{9}, \mathrm{~s}-\mathrm{C}_{4} \mathrm{H}_{9}, \mathrm{C}_{4} \mathrm{H}_{8}-1\right.$, s$\mathrm{C}_{4} \mathrm{H}_{9} \mathrm{O}_{2}, \mathrm{C}_{4} \mathrm{H}_{8} \mathrm{OOH}$, and $\left.\mathrm{OC}_{4} \mathrm{H}_{7} \mathrm{OOH}\right)$. All steps are reversible, although, in practice, some reverse steps are negligible, and all of the unimolecular steps are in the high-pressure limit.

The mechanism in Table 1 can be described as follows: The first eleven steps in the table are all relevant to predicting properly the initial breakdown of n-butane over the full range of conditions of interest. Entries 1-9 are taken from [13]. In trying to improve predictions of laminar flame speeds [4-6], without decreasing the accuracies of predicted ignition delay times, different rates for steps 10-11, given in [24], for example [25,26], were tested, with the final selection being the best-justified values published in [27]; the resulting rates lie between those of [5] and [13]. 
Table 1: The elementary reactions of the n-butane mechanism with the specific reaction-rate constants; units are moles, cubic centimeters, seconds, kilocalories, Kelvin.

\begin{tabular}{|c|c|c|c|c|c|}
\hline Number & Reaction & $B_{n}$ & $\alpha_{n}$ & $E_{n}$ & Ref. \\
\hline 1 & $\begin{array}{l}\mathrm{C}_{4} \mathrm{H}_{10} \leftrightarrow \mathrm{C}_{2} \mathrm{H}_{5}+\mathrm{C}_{2} \mathrm{H}_{5} \\
\text { Low pressure limit } \\
\text { Troe: } 0.72 \quad 1500 \quad 0.0 \quad 1.00 \mathrm{E}+10\end{array}$ & $\begin{array}{l}2.72 \mathrm{E}+15 \\
4.72 \mathrm{E}+18\end{array}$ & $\begin{array}{l}0.0 \\
0.0\end{array}$ & $\begin{array}{l}75.60 \\
49.58\end{array}$ & [13] \\
\hline 2 & $\mathrm{C}_{4} \mathrm{H}_{10}+\mathrm{O}_{2} \leftrightarrow \mathrm{n}-\mathrm{C}_{4} \mathrm{H}_{9}+\mathrm{HO}_{2}$ & $6.00 \mathrm{E}+13$ & 0.0 & 52.34 & [13] \\
\hline 3 & $\mathrm{C}_{4} \mathrm{H}_{10}+\mathrm{O}_{2} \leftrightarrow \mathrm{s}-\mathrm{C}_{4} \mathrm{H}_{9}+\mathrm{HO}_{2}$ & $4.00 \mathrm{E}+13$ & 0.0 & 49.80 & [13] \\
\hline 4 & $\mathrm{C}_{4} \mathrm{H}_{10}+\mathrm{HO}_{2} \leftrightarrow \mathrm{n}-\mathrm{C}_{4} \mathrm{H}_{9}+\mathrm{H}_{2} \mathrm{O}_{2}$ & $4.08 \mathrm{E}+01$ & 3.59 & 17.16 & [13] \\
\hline 5 & $\mathrm{C}_{4} \mathrm{H}_{10}+\mathrm{HO}_{2} \leftrightarrow \mathrm{s}-\mathrm{C}_{4} \mathrm{H}_{9}+\mathrm{H}_{2} \mathrm{O}_{2}$ & $1.26 \mathrm{E}+02$ & 3.37 & 13.72 & [13] \\
\hline 6 & $\mathrm{C}_{4} \mathrm{H}_{10}+\mathrm{O} \leftrightarrow \mathrm{n}-\mathrm{C}_{4} \mathrm{H}_{9}+\mathrm{OH}$ & $1.13 \mathrm{E}+14$ & 0.0 & 7.85 & [13] \\
\hline 7 & $\mathrm{C}_{4} \mathrm{H}_{10}+\mathrm{O} \leftrightarrow \mathrm{s}-\mathrm{C}_{4} \mathrm{H}_{9}+\mathrm{OH}$ & $5.62 \mathrm{E}+13$ & 0.0 & 2.20 & [13] \\
\hline 8 & $\mathrm{C}_{4} \mathrm{H}_{10}+\mathrm{OH} \leftrightarrow \mathrm{n}-\mathrm{C}_{4} \mathrm{H}_{9}+\mathrm{H}_{2} \mathrm{O}$ & $1.05 \mathrm{E}+10$ & 0.97 & 1.586 & [13] \\
\hline 9 & $\mathrm{C}_{4} \mathrm{H}_{10}+\mathrm{OH} \leftrightarrow \mathrm{s}-\mathrm{C}_{4} \mathrm{H}_{9}+\mathrm{H}_{2} \mathrm{O}$ & $9.34 \mathrm{E}+07$ & 1.61 & -0.03 & [13] \\
\hline 10 & $\mathrm{C}_{4} \mathrm{H}_{10}+\mathrm{H} \leftrightarrow \mathrm{n}-\mathrm{C}_{4} \mathrm{H}_{9}+\mathrm{H}_{2}$ & $2.80 \mathrm{E}+06$ & 2.54 & 6.965 & {$[27]$} \\
\hline 11 & $\mathrm{C}_{4} \mathrm{H}_{10}+\mathrm{H} \leftrightarrow \mathrm{s}-\mathrm{C}_{4} \mathrm{H}_{9}+\mathrm{H}_{2}$ & $1.69 \mathrm{E}+06$ & 2.40 & 4.493 & [27] \\
\hline 12 & $\mathrm{n}-\mathrm{C}_{4} \mathrm{H}_{9} \leftrightarrow \mathrm{C}_{2} \mathrm{H}_{4}+\mathrm{C}_{2} \mathrm{H}_{5}$ & $3.50 \mathrm{E}+12$ & 0.463 & 29.47 & [13] \\
\hline 13 & $\mathrm{~s}-\mathrm{C}_{4} \mathrm{H}_{9} \leftrightarrow \mathrm{C}_{3} \mathrm{H}_{6}+\mathrm{CH}_{3}$ & $4.80 \mathrm{E}+10$ & 1.044 & 30.35 & [13] \\
\hline 14 & $\mathrm{C}_{4} \mathrm{H}_{8} \leftrightarrow \mathrm{C}_{3} \mathrm{H}_{5}+\mathrm{CH}_{3}$ & $1.00 \mathrm{E}+16$ & 0.0 & 72.89 & [28] \\
\hline 15 & $\mathrm{C}_{4} \mathrm{H}_{8}+\mathrm{H} \leftrightarrow \mathrm{C}_{2} \mathrm{H}_{3}+\mathrm{C}_{2} \mathrm{H}_{4}+\mathrm{H}_{2}$ & $6.60 \mathrm{E}+05$ & 2.54 & 6.763 & [28] \\
\hline 16 & $\mathrm{~s}-\mathrm{C}_{4} \mathrm{H}_{9}+\mathrm{O}_{2} \leftrightarrow \mathrm{s}-\mathrm{C}_{4} \mathrm{H}_{9} \mathrm{O}_{2}$ & $7.54 \mathrm{E}+12$ & 0.0 & 0.0 & [13] \\
\hline 17 & $\mathrm{~s}-\mathrm{C}_{4} \mathrm{H}_{9} \mathrm{O}_{2} \leftrightarrow \mathrm{C}_{4} \mathrm{H}_{8}+\mathrm{HO}_{2}$ & $5.04 \mathrm{E}+38$ & -8.11 & 40.49 & [13] \\
\hline 18 & $\mathrm{n}-\mathrm{C}_{4} \mathrm{H}_{9}+\mathrm{O}_{2} \leftrightarrow \mathrm{C}_{4} \mathrm{H}_{8}+\mathrm{HO}_{2}$ & 8.37E-01 & 3.59 & 12.00 & [13] \\
\hline 19 & $\mathrm{n}-\mathrm{C}_{4} \mathrm{H}_{9}+\mathrm{O}_{2} \leftrightarrow \mathrm{C}_{4} \mathrm{H}_{8} \mathrm{OOH}$ & $2.00 \mathrm{E}+12$ & 0.0 & 0.0 & {$[19,28]^{\mathrm{a}}$} \\
\hline 20 & $\mathrm{C}_{4} \mathrm{H}_{8} \mathrm{OOH} \leftrightarrow \mathrm{C}_{4} \mathrm{H}_{8}+\mathrm{HO}_{2}$ & $2.00 \mathrm{E}+12$ & 0.0 & 24.0 & [28] \\
\hline 21 & $\mathrm{C}_{4} \mathrm{H}_{8} \mathrm{OOH}+\mathrm{O}_{2} \leftrightarrow \mathrm{OH}+\mathrm{OC}_{4} \mathrm{H}_{7} \mathrm{OOH}$ & $3.50 \mathrm{E}+00$ & 2.234 & -16.56 & {$[13]^{\mathrm{a}}$} \\
\hline 22 & $\mathrm{OC}_{4} \mathrm{H}_{7} \mathrm{OOH} \leftrightarrow \mathrm{OH}+\mathrm{n}-\mathrm{C}_{3} \mathrm{H}_{7}+\mathrm{CO}_{2}$ & $3.00 \mathrm{E}+16$ & 0.0 & 41.50 & [13] \\
\hline
\end{tabular}

${ }^{\mathrm{a}}$ See text.

The unimolecular decomposition shown in the first step is known to be important for hightemperature ignition and for laminar flame speeds. Steps 2 and $3\left(\mathrm{C}_{4} \mathrm{H}_{10}+\mathrm{O}_{2}\right)$ are the essential chain-initiation reactions, while the $\mathrm{H}$-atom abstractions through $\mathrm{OH}$ and $\mathrm{H}$ attacks are very important for shock-tube and flow-reactor ignition delays, as well as for laminar burning velocities. In addition, if good results are to be obtained for low-temperature chemistry, then the $\mathrm{H}$-atom abstraction by $\mathrm{HO}_{2}$ must be included, since it is found to be significant for appropriately increasing the reactivity of the system in jet-stirred reactors and NTC ignition at temperatures 
above 700 K. Steps 6 and 7, of lesser importance, are included mainly because of internal consistency in that the mechanism retains the analogous steps for lower alkanes.

The n-butyl and s-butyl radicals, produced by the $\mathrm{H}$ abstraction, can decompose through $\beta$ scission to form ethane and ethyl or propene and a methyl radical (steps 12 and 13), in competition with their oxygen additions that initiate the subsequent low-temperature chemistry. The rate parameters in the table for these two steps are taken from [13].

The butene $\left(\mathrm{C}_{4} \mathrm{H}_{8}\right)$ shown in the table is $\mathrm{C} 4 \mathrm{H} 8$-1, its symmetric counterpart having been found in our computations to play a negligible role and therefore having been excluded a part of the reduction. The rate parameters for its consumption, steps 14-15, are chosen from our n-heptane sub-mechanism [28] for consistency with the base mechanism, although the resulting rate differ from those of [11-13] by less than a factor of 2, with the exception that the rate of step 14 is about 5 times that in [13].

The rate parameters for steps 16, 17, and 18 were taken from [13]. Steps 16 and 17, the $\mathrm{O}_{2}$ addition to the s-butyl radical to form s-hydroperoxy-butyl and its decomposition to form hydroperoxyl and butene, respectively, were found in the present investigation to constitute a sequence that inhibits the low-temperature branching, which proceeds through the n-butyl radical instead, a well-known tendency, although not as extreme in other mechanisms as in the present selection.

In analogy with our earlier approaches [19, 28], we approximate all of the low-temperature chemistry as being obtained from the n-butyl radical and also place the resulting $\mathrm{RO}_{2}$ radical in steady state to eliminate it (as justified by our many trial computations), recognizing that, although not entirely true fundamentally, it helps considerably in reduction, while not degrading the quality of the auto-ignition predictions. For the $\mathrm{C}_{4}$ normal alkane, this is supported experimentally by the recent study of Eskola et al. [17], which concludes that, over the range of 
conditions of the analysis, the QOOH radical derived from n-butyl (entry 19 of Table 1) is the main radical reactant, with 4-hydroperoxy-2-butyl $+\mathrm{O}_{2}$ (entry 21), leading to 3hydroperoxybutanal $\left(\mathrm{OC}_{4} \mathrm{H}_{7} \mathrm{OOH}\right.$, entry 22$)$, which was the sole ketohydroperoxide that they observed. A sensitivity analysis, performed during the present research, also supported this conclusion. It is noteworthy that the reverse of the first $\mathrm{O}_{2}$ addition in step 19 is of great importance for producing the NTC behavior of n-butane in our computations.

The value given for the rate of step 19 in the table, which lies in the center of the range of values employed in the literature on n-butane $[11,13,22]$, is the same as the value that we have previously employed in the analogous steps for propane and for heptane, the rate of this addition step being rather insensitive to the size of the alkyl radical. This step includes the addition to form $\mathrm{RO}_{2}$, followed by isomerization to the hydroperoxyalkyl radical $\mathrm{C}_{4} \mathrm{H}_{8} \mathrm{OOH}$ shown, the isomerization being rapid enough that its rate need not be considered, as mentioned above and shown in our earlier work $[19,28]$, where $\mathrm{RO}_{2}$ has similarly been eliminated through its steady state.

The species formed in this first oxygen-addition step of the low-temperature mechanism can disappear in a number of different pathways. Competing with the second oxygen addition is the decomposition to hydroperoxyl and a conjugate alkene, shown in step 20, which is one of a number of possible decompositions, such as $\mathrm{OH}$ elimination to produce aldehydes or cyclic ethers $[11,13,22]$, or possibly smaller olefins and aldehydes. Our calculations including these other pathways, with literature rates, indicated that they were of lesser importance, as also was found in our earlier work $[19,28]$, and therefore they are also neglected in the present mechanism. The rate parameters selected for step 20 are identical to those that we employed previously [28] for $\mathrm{C}_{7} \mathrm{H}_{14} \mathrm{OOH}$ in the $\mathrm{C}_{7}$ mechanism, since the resulting rate lies in the range of available literature $[11,20,23]$ below $1000 \mathrm{~K}$ (where it is important) and contributes to the 
accuracy of the predictions, improving agreements. It implicitly includes the corresponding decomposition from $\mathrm{RO}_{2}$, through its assumed steady state, and it thus reflects the overall effect of quite a number of steps that would be present in fully detailed mechanisms.

Step 21 describes the overall effect of the second $\mathrm{O}_{2}$ addition. It is the result of employing the steady-state approximation for the intermediate adduct species and therefore exhibits only the decomposition products, the carbonyl compound and $\mathrm{OH}$. The negative activation energy shown, essential for NTC behavior, is a consequence of the heat of re-dissociation of the steady-state adduct exceeding the activation energy for its decomposition. The mechanism [13], from which this rate is taken, shows that the decomposition occurs from the isomer $\mathrm{O}_{2} \mathrm{QOOH}$ instead of the species initially formed after the second $\mathrm{O}_{2}$ addition, but, again, the isomerization to $\mathrm{O}_{2} \mathrm{QOOH}$ is sufficiently rapid that the initial species need not be included.

For the last of the low-temperature-chemistry steps, the rate parameters for the branching decomposition in entry 22 are taken for NC4KET13 from [13], which corresponds to the 3hydroperoxybutanal described above, according to [17], with modifications in the preexponential factor (double the original) to match auto-ignition times better in the NTC range. The carbon-containing species selected for this single step of ketohydroperoxide decomposition differ from those appearing in many of the channels found in the literature (typically involving radicals containing two carbon atoms), but in our reduced mechanism they improve agreement with recently reported measurements at normal atmospheric pressure in an isothermal jet-stirred reactor, the $\mathrm{C}_{2}$ species being too reactive. In general, for overall steps such as 15 and 22 , there are multiple paths leading to different sets of products, and our approach has been to choose just one, sometimes increasing its rate to allow for the effects of the others on removal of key species, with the correct most-reactive product (if any) preserved, but with less-reactive products selected to eliminate (or at least minimize) the need to introduce additional species into the $\mathrm{C}_{3}$ 
sub-mechanism, while not degrading predictions, since these products exert less influence on predictions. This type of "lumping" already is present in the heptane and JP-10 sub-mechanisms of the San Diego mechanism, for example.

\section{VALIDATION TESTS}

The conventional first testing ground for chemical-kinetic combustion mechanisms is the prediction of laminar burning velocities. For any mechanism to be successful, it must at least provide reasonable agreement with measured burning velocities, within experimental uncertainties. In a sense, this is not entirely fair because burning velocities depend on transport properties as well as on the chemical kinetics, so disagreements can arise from improper transport descriptions. The first tests to be reported here nevertheless concern burning velocities. Following the burning-velocity tests, comparisons will be made with experimental auto-ignition delay times. Such tests are free from transport-property influences, although they do have other uncertainties, such as the definitions of ignition delays and reactor residence-time inaccuracies. The experimental ignition times are determined from measured pressure-rise onsets, which are expected to be in reasonable agreement with the temperature-inflection criteria employed here computationally for the experiments addressed, and the residence-time inaccuracies in the experiments to be considered are not large. High-temperature ignition delays are tested before addressing the NTC range. The computer program FlameMaster [29] was mainly used in this work, and CHEMKIN II [30] was employed for the isothermal jet-stirred-reactor calculations. In the laminar flame-speed computations with FlameMaster [29] using the thermo-diffusion option, convergence was achieved with 330 grid points. 
Figure 1: Comparisons of predicted and measured laminar flame speeds of $\mathrm{n}$-butane/air mixtures as a function of the equivalence ratio.

The experiments shown in Fig. 1, for burning-velocity comparisons, were performed at room temperature ( $295 \mathrm{~K}$ to $298 \mathrm{~K}$ ) and normal atmospheric pressure. It is seen in Fig. 1 that these laminar flame speeds are well reproduced by the present chemistry, including their dependence on equivalence ratio, within experimental uncertainties, which are largest near stoichiometric conditions. There are small tendencies toward under-prediction at stoichiometric and rich conditions. Under the conditions tested, it was found that the n-butane sub-mechanism developed here produces agreements with experiments on burning velocities that are comparable with the agreements obtained for other fuels or with other mechanisms.

a)

b)

Figure 2: Measured and computed species profiles: a) Ignition times for $2.5 \% \mathrm{n}-\mathrm{C}_{4} \mathrm{H}_{10}, 16.25 \%$ $\mathrm{O}_{2}, 81.25 \% \mathrm{Ar}, \mathrm{p} \approx 10$ atm $\left.[6,13] ; \mathrm{b}\right)$ Effect of equivalence ratio on high-temperature ignition times for $\mathrm{n}-\mathrm{C}_{4} \mathrm{H}_{10}$ oxidation in air, $\mathrm{p} \approx 2$ atm [13].

Concerning ignition delays, computationally, the ignition time was defined as the time required to reach the inflection point of the temperature-time profile, that is, the maximum value of the slope of the curve, under adiabatic, isochoric conditions. In the NTC regime, this is the second inflection because an inflection point also occurs earlier, during the first stage of ignition. Figure 2a compares predictions of the present mechanism with measurements $[6,13]$ in the temperature range of $1050-1400 \mathrm{~K}$ and at $10 \mathrm{~atm}$. The experiments were performed in a shock tube with a gas mixture of $2.5 \% \mathrm{n}-\mathrm{C}_{4} \mathrm{H}_{10}, 16.25 \% \mathrm{O}_{2}, 81.25 \%$ Ar. The agreements are good, considering 
uncertainties in the measurements, and they are comparable with agreements found for other high-temperature data on tests not shown here.

Figure $2 \mathrm{~b}$ illustrates the effect of equivalence ratio on ignition delay times, namely for 2.0, 1.0, and 0.5 in air at a pressure of approximately 2 atm [13]. At these conditions of low pressure and relatively high temperature, fuel-lean mixtures are the most reactive, while fuel-rich mixtures are the slowest to ignite at any given temperature. This is common to all alkane fuels under these high-temperature conditions, where the rate of the dominant chain-branching step $\mathrm{H}+\mathrm{O}_{2}=\mathrm{O}+$ $\mathrm{OH}$ increases with increasing concentrations of molecular oxygen. The curves in this figure are seen to converge at about $1225 \mathrm{~K}$, where this high-temperature path becomes slower than a lowtemperature path less strongly dependent on this particular branching.

Of greater interest than these high-temperature results are ignition-time comparisons in the NTC region. Figure 3 (a, b, and c) shows comparisons of ignition delay times at different pressures for stoichiometric, rich, and lean conditions, respectively, in mixtures of n-butane and air. The early experimental data for 10 atm are from [8-9], while more recent experimental results are taken from [12-13] for comparison. The predictions of the model show qualitatively and quantitatively good agreement with the experiments for the complete range of temperature and pressure of the experimental data, especially in view of the very large differences between results of different experiments carried out under the same conditions. These differences have been observed and discussed in the literature [13]. For example, at some conditions the model under-predicts ignition delays, an effect that may arise from heat losses during experiments, which have been addressed previously [13] but are difficult to estimate accurately and therefore are not addressed in the present calculations. The low-temperature boundary of the NTC region increases with pressure more rapidly than the high-temperature boundary, thus causing the NTC zone to narrow 
with increasing pressure, as is also typical of other normal alkanes. There also is a narrowing with increasing equivalence ratio, accompanied in that case by steepening of the strength of the NTC ignition-time variations. The predicted influences of both pressure and equivalence ratio on ignition delays are in close accord with these aspects of the measurements [8-9, 12-13].

a)
b)

Figure 3: Comparisons of ignition times for n-butane/air mixtures at different pressures for: a) Stoichiometric mixtures; b) Rich mixtures; c) Lean mixtures.

The recently reported experiments at normal atmospheric pressure, in which isothermal flowreactor measurements of species concentrations were made at fixed residence times for different temperatures [16], afford an opportunity to extend the range of tests of the mechanism. In these comparisons, calculations were made for closed, homogeneous, zero-dimensional systems at constant pressure, but now under isothermal rather than adiabatic conditions, by using Chemkin II [30]. The residence time was taken to be $6 \mathrm{~s}$ at $1 \mathrm{~atm}$, as in the experiment [16]. Figure 4 compares the measured and predicted $\mathrm{O}_{2}$ and n-butane mole-fraction profiles as functions of temperature for a mixture composition $n-\mathrm{C}_{4} \mathrm{H}_{10} / \mathrm{O}_{2} / \mathrm{He}$ of $0.023 / 0.15 / 0.827$ [16]. Since these results for the reactant consumption are the most sensitive to the chemical mechanism selected, results for other species are not shown. The figure shows that the $\mathrm{O}_{2}$ and n-butane concentrations begin to decrease around $600 \mathrm{~K}$, and then increase above $650 \mathrm{~K}$, consistent with the NTC region. This is a consequence of the two-stage chemical-kinetic phenomena and in that sense provides a test of the mechanism. Obtaining the good comparisons with the experimental results shown 
here (noticeably better than with the base $C_{4}$ mechanism selected [13] prior to adjustment, shown in the dashed curves) entailed the previously mentioned adjustments in the product species from the ketohydroperoxide decomposition resulting in step 22. This particular selection of the set of reaction products from the multiple paths that actually occur was made specifically because the introduction of $n-\mathrm{C}_{3} \mathrm{H}_{7}$ here contributed to decreasing the n-butane low-temperature oxidation reactivity in these atmospheric-pressure experiments, without any significant changes in predictions of low-temperature ignition at high pressures with our reduced mechanism.

a)

b)

Figure 4: Mole fraction profiles as functions of temperature for a mixture composition of $\mathrm{n}$ $\mathrm{C}_{4} \mathrm{H}_{10} / \mathrm{O}_{2} / \mathrm{He}$ of $0.023 / 0.15 / 0.827$ in a 1 atm jet stirred reactor [16]: a) $\mathrm{O}_{2}$; b) $n-\mathrm{C}_{4} \mathrm{H}_{10}$.

\section{HISTORICAL CONTEXT}

The contribution of this work fulfills a two-fold purpose. One purpose is to extend the short mechanism identified in the abstract to include normal butane, and the other is to further test our substantially reduced mechanism for the low-temperature combustion chemistry of normal alkanes.

The short mechanism was developed initially to address high-temperature combustion chemistry, beginning with hydrogen and then expanding to carbon monoxide and methane, including a submechanism for the chemistry of production of oxides of nitrogen, motivated by the great interest in pollution problems at the time. It was next extended to include ethane and the $\mathrm{C}_{3}$ hydrocarbons, propane, propene, and propyne, as well as the alcohols methanol and ethanol, and, 
because of technical applications, short sub-mechanisms were added early on for n-heptane and JP-10, the former requiring components for pentene, pentadiene, butene, and butadiene, all restricted to high-temperature combustion chemistry. In addition, improvements in elementary rates, especially for the hydrogen sub-mechanism, have been introduced from time to time, as new information became available. In line with our interest in enlarging the mechanism to include higher hydrocarbons and higher alcohols, the present work adds high-temperature combustion chemistry for n-butane as well, completing the content through $\mathrm{C}_{4}$ 's, with the exception of some species such as isobutane, which, however, could easily be added, and others, such as aromatics, which would require larger mechanisms. Extensions to propanol and butanol also remain for the future.

Large discrepancies between predictions and measurements related to propane safety at lower temperatures motivated extending the mechanism to include low-temperature combustion chemistry [19]. To accomplish that without greatly enlarging the short mechanism, reductions were introduced not only by eliminating elementary steps and paths of lesser importance, as had been done before (thereby precluding addressing various side processes and products), but also by invoking steady-state approximations to eliminate intermediate species that served merely to carry the chains of the normal alkanes. Following that accomplishment for ethane and propane [19] and for heptane [26], the present work adds butane, based on the same type of reduction explained previously [19]. It seems noteworthy that replacement of the many isomers addressed in detailed mechanisms for higher normal alkanes with a single isomer at each stage along the route of the two sequential oxygen additions in the low-temperature chemistry, initially envisioned as a useful approximation, which, however, did not reflect reality, apparently, in view of recent observations [17], may indeed provide a better approximation to the true mechanism for n-butane than might reasonably have been expected in advance. While there has been recent 
movement in the chemical-kinetics community towards developing reduced chemistry through methods of the type that we employ, none of that work has considered mechanisms nearly as simple as ours, except for the n-heptane mechanism developed by N. Peters and his co-workers [31]. The examples set by Peters in these sorts of approaches to the understanding of combustion chemistry will be sorely missed in the future.

\section{ACKNOWLEDGMENTS}

JCP acknowledges support from Tecnológico Nacional de México and CONACYT. CT acknowledges the DGAPA, UNAM, for supporting a sabbatical leave at ELTE University in Hungary. FAW received support from the US National Science Foundation through award \# CBET-1404026.

\section{REFERENCES}

[1] N.M. Marinov, W.J. Pitz, C.K. Westbrook, A.M. Vincitore, M.J. Castaldi, S.M. Senkan, C.F. Melius, Aromatic and polycyclic aromatic hydrocarbon formation in a laminar premixed nbutane flame, Combust. Flame 114 (1998) 192-213.

[2] S.G. Davis, C.K. Law, Determination of and fuel structure effects on laminar flame speeds of C1 to C8 hydrocarbons, Combust. Sci. Technol. 140 (1998) 427-449.

[3] T. Hirasawa, C.J. Sung, A. Joshi, Z. Yang, H. Wang, C.K. Law, Determination of laminar flame speeds using digital particle image velocimetry: binary fuel blends of ethylene, n-butane, and toluene, Proc. Combust. Inst. 29 (2002) 1427-1434.

[4] K.J. Bosschaart, L.P.H. De Goey, The laminar burning velocity of flames propagating in mixtures of hydrocarbons and air measured with the heat flux method, Combust. Flame 136 
(2004) 261-269.

[5] E. Ranzi, A. Frassoldati, R. Grana, A. Cuoci, T. Faravelli, A.P. Kelley, C.K. Law, Hierarchical and comparative kinetic modeling of laminar flame speeds of hydrocarbon and oxygenated fuels, Prog. Energ. Combust. 38 (2012) 468-501.

[6] A. Burcat, K. Scheller, A. Lifshitz, Shock-tube investigation of comparative ignition delay times for C1-C5 alkanes, Combust. Flame 16 (1971) 29-33.

[7] D.C. Horning, D.F. Davidson, R.K.J. Hanson, Study of the high-temperature autoignition of n-alkane/O/Ar mixtures, J. Propul. Power 18 (2002) 363-371.

[8] J.F. Griffiths, P.A. Halford-Maw, D.J. Rose, Fundamental features of hydrocarbon autoignition in a rapid compression machine, Combust. Flame 95 (1993) 291-306.

[9] R. Minetti, M. Ribaucour, M. Carlier, C. Fittschen, L.R. Sochet, Experimental and modeling study of oxidation and autoignition of butane at high pressure, Combust. Flame 96 (1994) 201211.

[10] R.D. Wilk, R.S. Cohen, N.P. Cernansky, Oxidation of n-butane: transition in the mechanism across the region of negative temperature coefficient, Ind. Eng. Chem. Res. 34 (1995) 22852297.

[11] P. Gaffuri, T. Faravelli, E. Ranzi, N.P. Cernansky, D. Miller, A. d'Anna, A. Ciajolo, Comprehensive kinetic model for the low temperature oxidation of hydrocarbons, AIChE journal 43 (1997) 1278-1286.

[12] S. Gersen, A.V. Mokhov, J.H. Darmeveil, H.B. Levinsky, Ignition properties of n-butane and iso-butane in a rapid compression machine, Combust. Flame 157 (2010) 240-245. 
[13] D. Healy, N.S. Donato, C.J. Aul, E.L. Petersen, C.M. Zinner, G. Bourque, H.J. Curran, nButane: Ignition delay measurements at high pressure and detailed chemical kinetic simulation Combust. Flame 157 (2010) 1526-1539.

[14] F. Battin-Leclerc, O. Herbinet, P.A. Glaude, R. Fournet, Z. Zhou, L. Deng, F. Qi, Experimental confirmation of the low-temperature oxidation scheme of alkanes, Angew. Chem. Int. Edit. 49 (2010) 3169-3172.

[15] F. Battin-Leclerc, O. Herbinet, P.A. Glaude, R. Fournet, Z. Zhou, L. Deng, F. Qi, New experimental evidences about the formation and consumption of ketohydroperoxides, Proc. Combust. Inst. 33 (2011) 325-331.

[16] C. Bahrini, P. Morajkar, C. Schoemaecker, O. Frottier, O. Herbinet, P.A. Glaude, F. BattinLeclerc, C. Fittschen, Experimental and modeling study of the oxidation of n-butane in a jet stirred reactor using cw-CRDS measurements, Phys. Chem. Chem. Phys. 15 (2013), 1968619698.

[17] A.J. Eskola, O. Welz, J. Zádor, I.O. Antonov, L. Sheps, J.D. Savee, C. A. Taatjes, Probing the low-temperature chain-branching mechanism of n-butane autoignition chemistry via timeresolved measurements of ketohydroperoxide formation in photolytically initiated n-C4H10 oxidation, Proc. Combust. Inst. 35 (2015) 291-298.

[18] H.J. Curran, P. Gaffuri, W.J. Pitz, C.K. Westbrook, A comprehensive modeling study of iso-octane oxidation, Combust. Flame 129 (2002) 253-280.

[19] J.C. Prince, F.A. Williams, Short chemical-kinetic mechanisms for low-temperature ignition of propane and ethane, Combust. Flame 159 (2012) 2336-2344. 
[20] V. Warth, N. Stef, P.A. Glaude, F. Battin-Leclerc, G. Scacchi, G.M. Come, Computer-aided derivation of gas-phase oxidation mechanisms: application to the modeling of the oxidation of nbutane, Combust. Flame 114 (1998) 81-102.

[21] J.M. Simmie, Detailed chemical kinetic models for the combustion of hydrocarbon fuels, Prog. Energ. Combust. 29 (2003) 599-634.

[22] M.I. Strelkova, A.A. Safonov, L.P. Sukhanov, S.Y. Umanskiy, I.A. Kirillov, B.V. Potapkin, A.M. Tentner, Low temperature n-butane oxidation skeletal mechanism, based on multilevel approach, Combust. Flame 157 (2010) 641-652.

[23] M. Cord, B. Sirjean, R. Fournet, A. Tomlin, M. Ruiz-Lopez, F. Battin-Leclerc, Improvement of the modeling of the low-temperature oxidation of n-butane: study of the primary reactions, J. Phys. Chem. A, 116 (2012) 6142-6158.

[24] J.A. Manion, et al. NIST Chemical Kinetics Database, NIST Standard Reference Database 17, Version 7.0 (Web Version), National Institute of Standards and Technology, Gaithersburg, Maryland, 20899-8320. Web address: http://kinetics.nist.gov/.

[25] R.R. Baldwin, R.W. Walker, Rate constants for hydrogen+ oxygen system, and for H atoms and OH radicals+ alkanes, J. Chem. Soc. Farad. T1 75 (1979) 140-154.

[26] J.E. Nicholas, G.L. Vaghjiani, Reaction probabilities, cross sections, and threshold energies in the reaction of isotopically pure H atoms and n-butane, J. Chem. Phys. 91 (1989) 5121-5123. [27] J.A. Manion, D.A. Sheen, I.A. Awan, Evaluated Kinetics of the Reactions of H and CH3 with n-Alkanes: Experiments with n-Butane and a Combustion Model Reaction Network Analysis, J. Phys. Chem. A, 119(2015) 7637-7658.

[28] J.C. Prince, F.A. Williams, Revised short mechanism for the low-temperature ignition of n- 
heptane for a wider pressure range, Fuel 150 (2015) 730-731.

[29] H. Pitsch. FlameMaster, Computer program for 0D-1D combustion calculations.

[30] R.J. Kee, F.M. Rupley, J.A. Miller. (1989). Chemkin-II: A Fortran chemical kinetics package for the analysis of gas-phase chemical kinetics (No. SAND-89-8009). Sandia National Labs., Livermore, CA (USA).

[31] N. Peters, G. Paczko, R. Seiser, K. Seshadri, Temperature cross-over and non-thermal runaway at two-stage ignition of n-heptane, Combust. Flame 128 (2002) 515-531. 


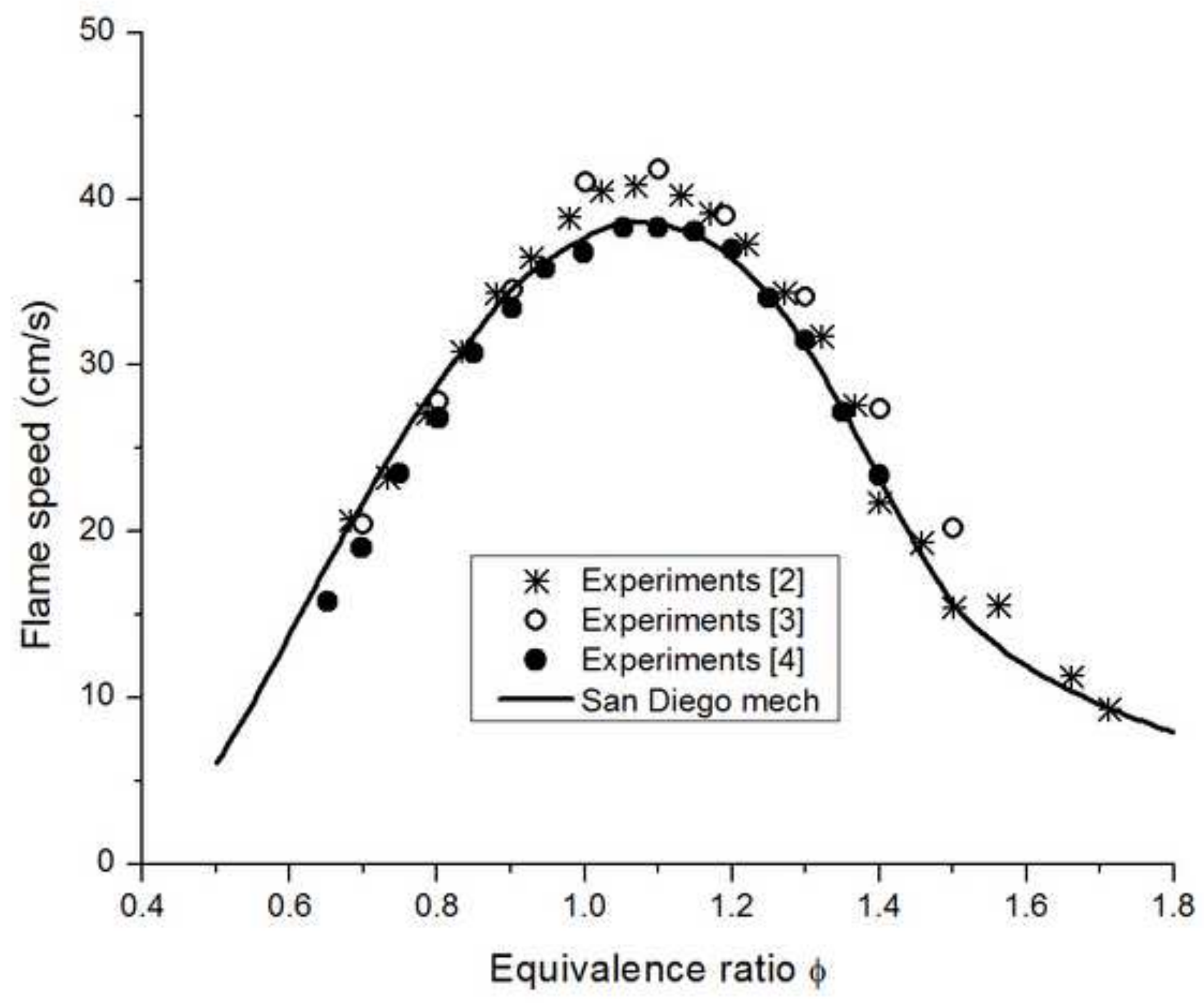




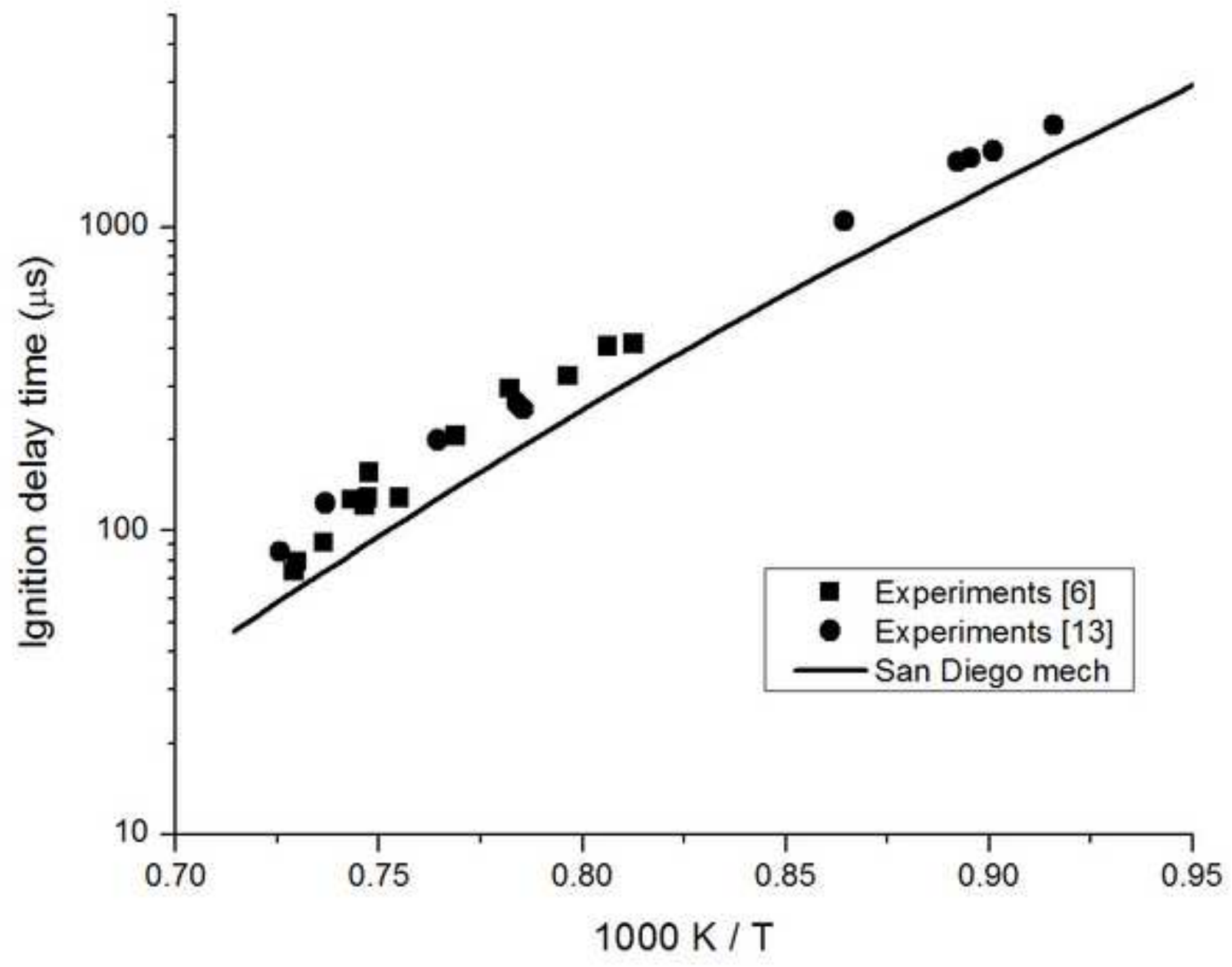




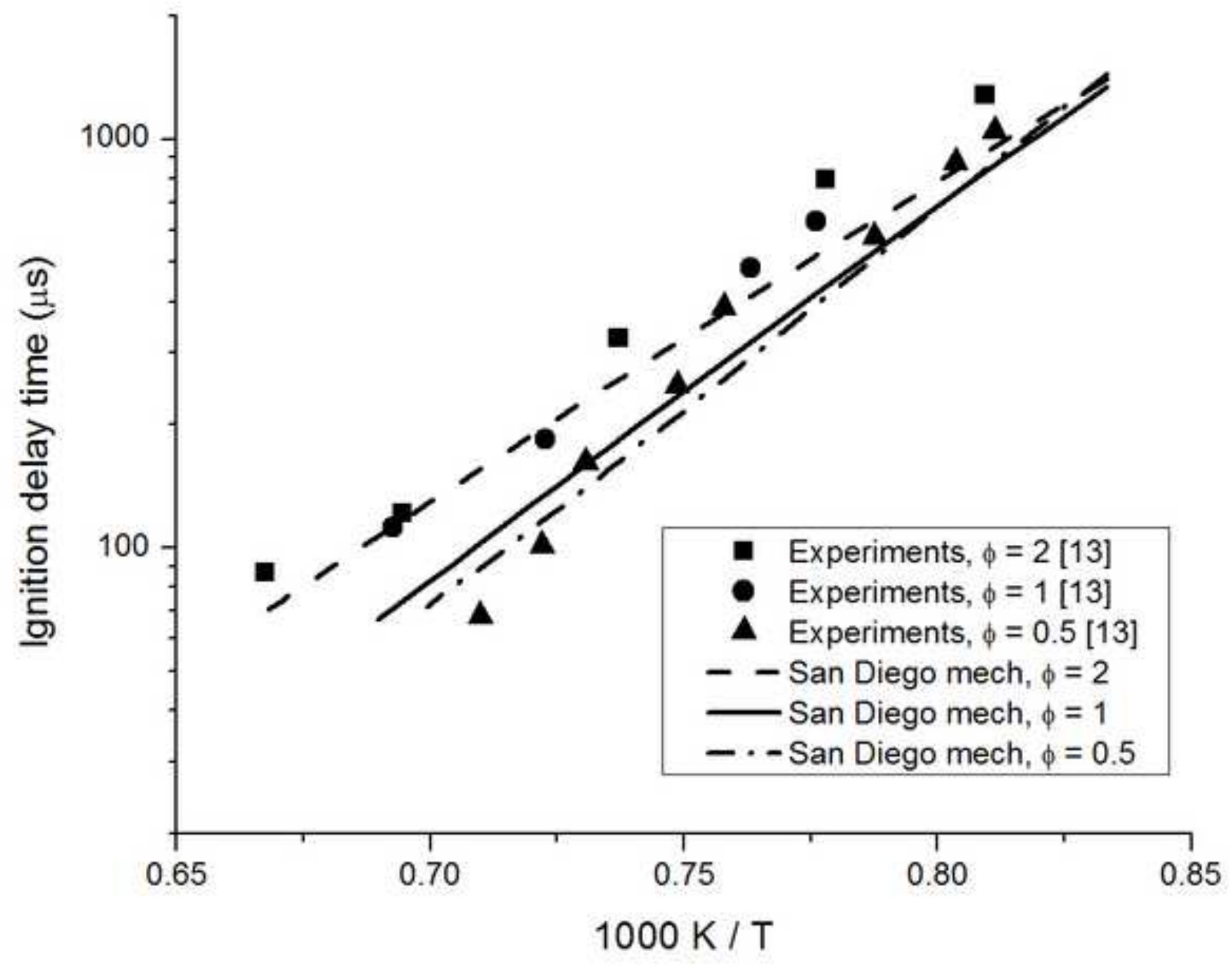




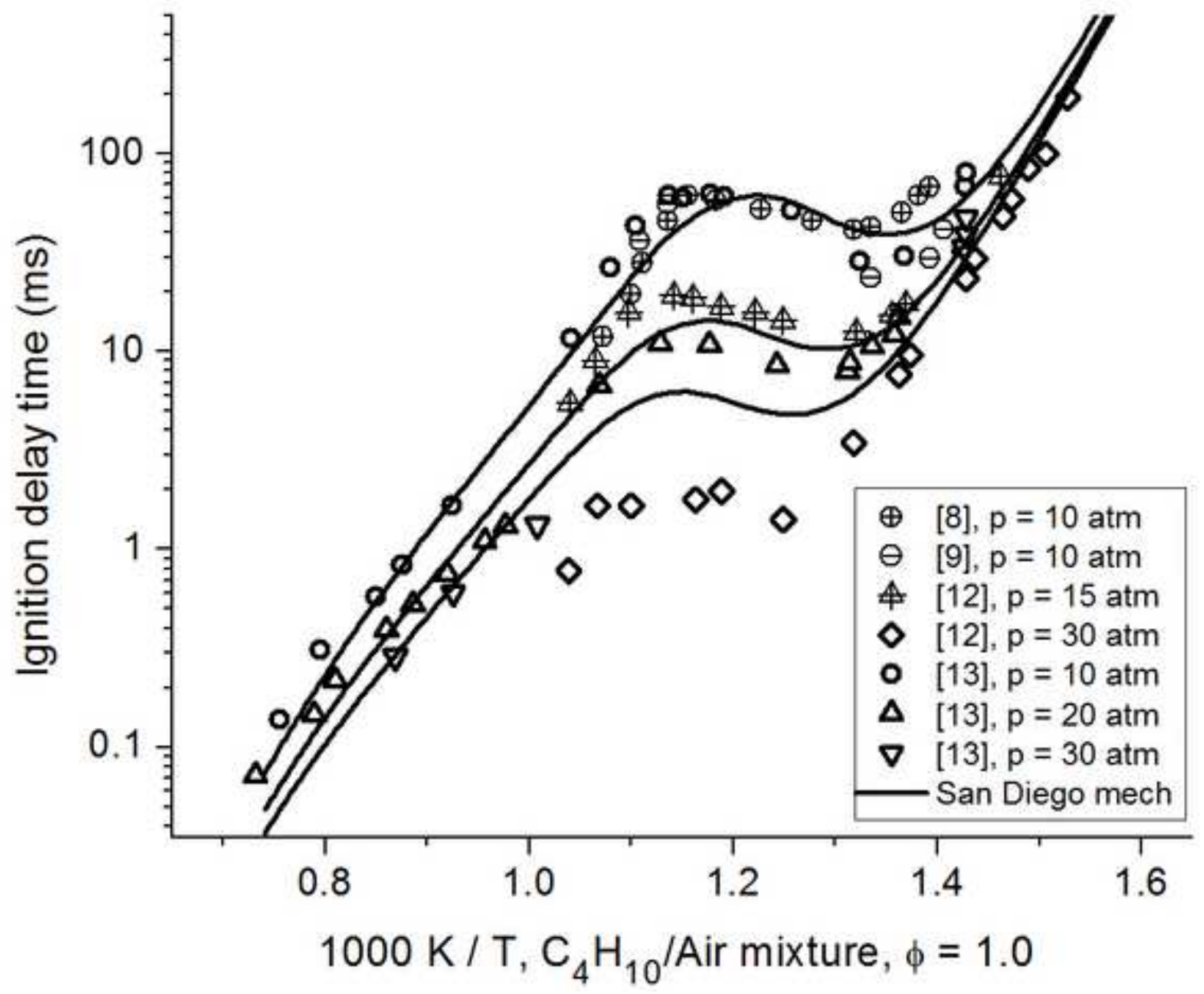




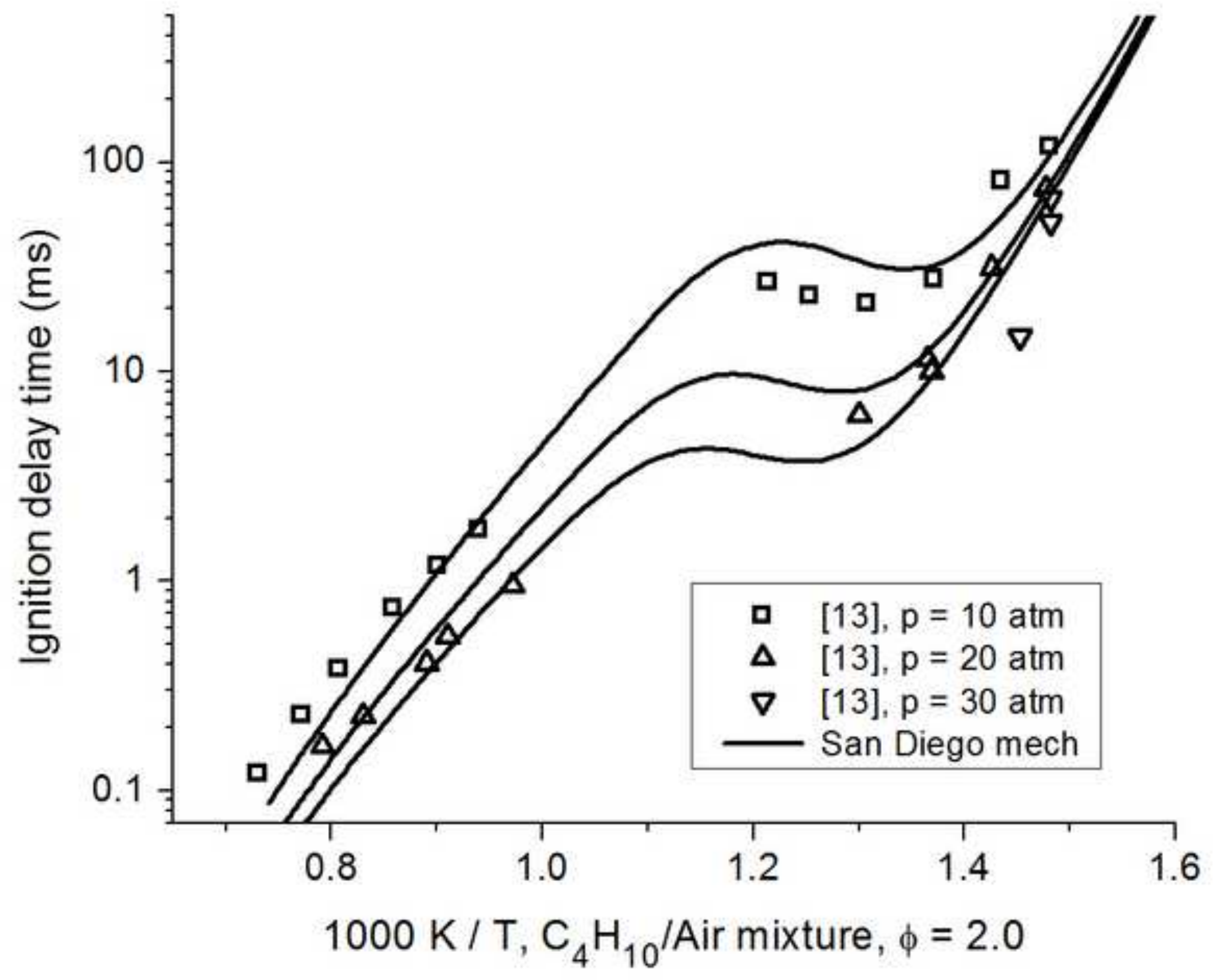




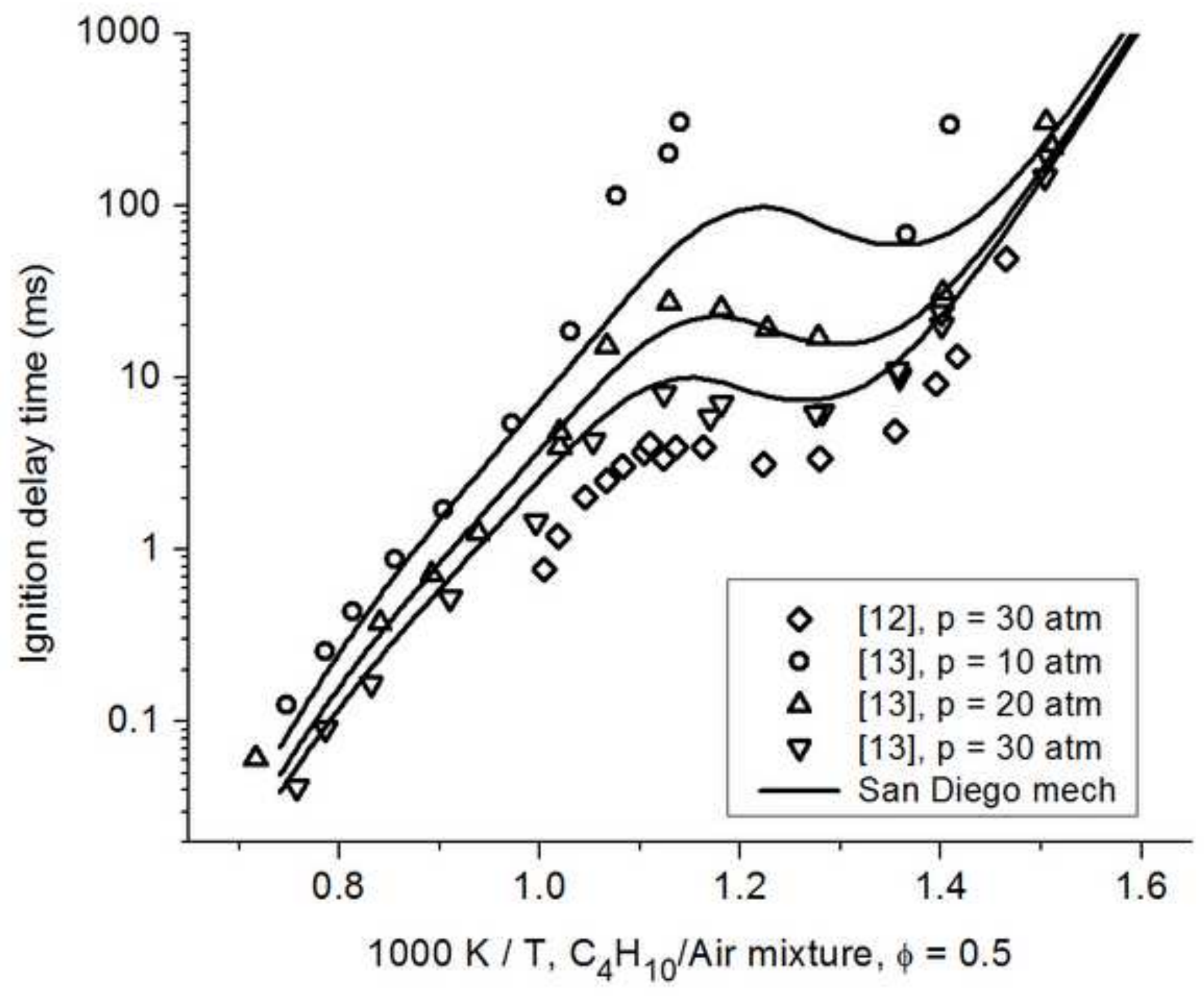




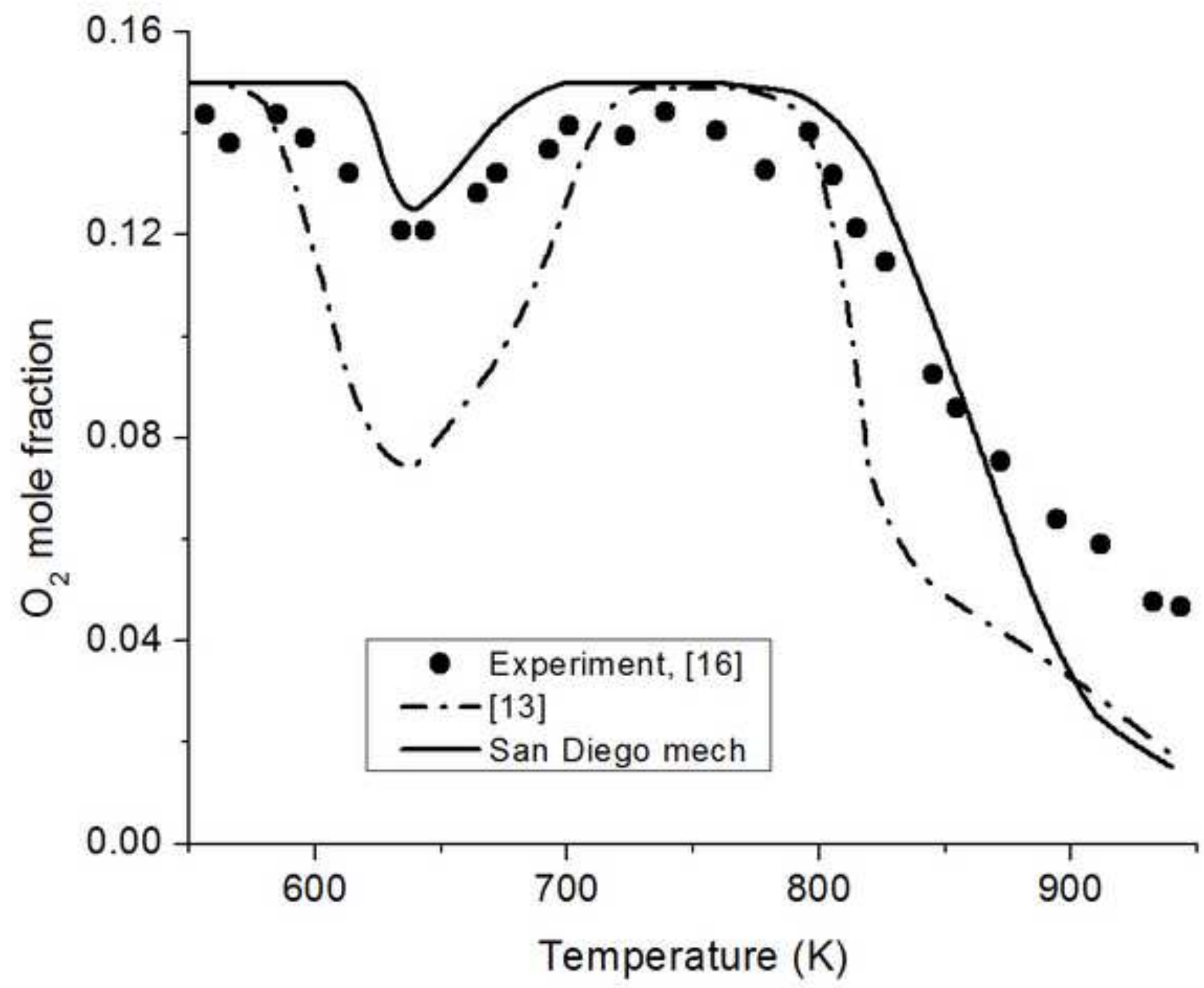




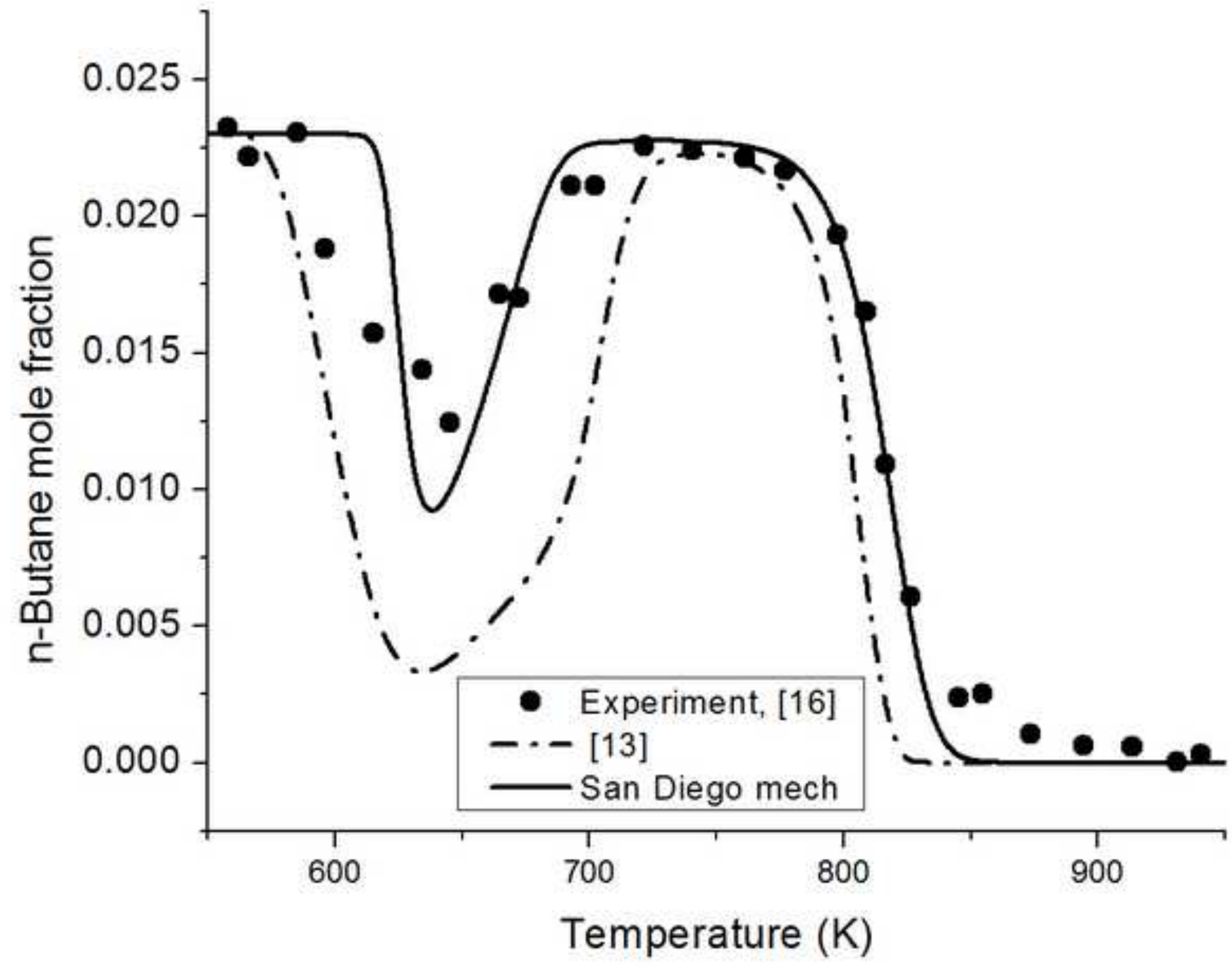

